Virginia Commonwealth University VCU Scholars Compass

\title{
Effect of Au coating on the magnetic and structural properties of Fe nanoclusters for use in biomedical applications: A density-functional theory study
}

Q.Sun

PMUSA, Virginia Commonwealth University

A. K. Kandalam

Virginia Commonwealth University

Q.Wang

Virginia Commonwealth University

See next page for additional authors

Follow this and additional works at: http://scholarscompass.vcu.edu/phys_pubs

Part of the Physics Commons

Sun, Q. Kandalam, A. K., Wang, Q. et al. Effect of Au coating on the magnetic and structural properties of Fe nanoclusters for use in biomedical applications: A density-functional theory study. Physical Review B, 73, 134409 (2006). Copyright (C) 2006 American Physical Society.

\section{Downloaded from}

http://scholarscompass.vcu.edu/phys_pubs/83

This Article is brought to you for free and open access by the Dept. of Physics at VCU Scholars Compass. It has been accepted for inclusion in Physics Publications by an authorized administrator of VCU Scholars Compass. For more information, please contact libcompass@vcu.edu. 
Authors

Q. Sun, A. K. Kandalam, Q. Wang, Puru Jena, Y. Kawazoe, and M. Marquez 


\title{
Effect of Au coating on the magnetic and structural properties of Fe nanoclusters for use in biomedical applications: A density-functional theory study
}

\author{
Q. Sun,,${ }^{1,2} *$ A. K. Kandalam, ${ }^{2}$ Q. Wang, ${ }^{2}$ P. Jena, ${ }^{2}$ Y. Kawazoe, ${ }^{3}$ and M. Marquez ${ }^{1}$ \\ ${ }_{1}^{1}$ Interdisciplinary Network of Emerging Science and Technologies (I'NEST Group), PMUSA, Richmond, Virginia 23234, USA \\ ${ }^{2}$ Physics Department, Virginia Commonwealth University, Richmond, Virginia 23284, USA \\ ${ }^{3}$ Institute for Material Research, Tohoku University, Sendai 980-8577, Japan
}

(Received 25 January 2006; published 7 April 2006)

\begin{abstract}
In this paper, we report the first systematic theoretical study of gold-coated iron nanoclusters, aiming at understanding the magnetic properties of this core-shell structure used in biomedical applications. The calculations based on density-functional theory focus on the effect of gold coating on the magnetic and structural properties of iron clusters of various sizes, and the reaction of the bare and coated iron clusters with oxygen. Our results show that the magnetic moment of iron nanocore with gold coating is still significantly higher than that in bulk Fe; the coupling between Fe atoms remained ferromagnetic and is insensitive to the thickness of the Au coating. Furthermore, oxygen remains molecular on a gold-coated Fe nanoparticle while it dissociates on a bare Fe nanoparticle. The improved chemical stability by gold coating prevents the iron core from oxidation as well as the coalescence and formation of thromboses in the body. Thus it is shown that gold coating is very promising for the magnetic particles to be functionalized for targeted drug delivery.
\end{abstract}

DOI: 10.1103/PhysRevB.73.134409

PACS number(s): 75.75.+a, 73.22.-f, 31.15.Ar, 71.15.Nc

\section{INTRODUCTION}

Conventional methods of treating malignant tumors such as surgery, radiation, and/or chemotherapy are either invasive or have adverse side effects. A desired goal in cancer therapy for many years has been to find ways by which cancer cells can be selectively destroyed without damaging normal cells. Nanostructured particles which have the same length scales as those of tumors provide some attractive possibilities where this noble goal may some day be achieved. In particular, the magnetically directed drug delivery combined with hyperthermia can greatly improve the performance of current procedures. The strategy is to implant a nanoparticle near a cancer cell that can be heated through near infrared (NIR) light or an alternating magnetic field. The resulting heat can then destroy the tumor cells without damaging the healthy tissues. Since the magnetic field can penetrate deep into the tissue, the use of magnetic fluid hyperthermia provides a versatile method to treat a variety of tumors such as anaplastic astrocytomas or glioblastomas. An ideal nanoparticle for this application should be a strong magnet, biocompatible, and resistant to corrosion as well as aggregation.

The conventional magnetic nanoparticles that are widely used in experiments and animal testing involve iron oxides. However, the magnetic strength of iron oxides is not as high as that of pure iron and there is significant interest in developing alternative high moment nanoparticles for specific biomedical applications. In fact, the ability to control size, shape, and composition of magnetic iron nanoparticles can provide flexibility for applications in cell labeling, magnetic resonance imaging (MRI), drug delivery, and DNA separation. ${ }^{1-3}$ Unfortunately, bare Fe particles cannot directly be used for the following reasons: (1) Free iron is toxic because of its propensity to induce the formation of dangerous free radicals. (2) They can easily aggregate to form larger particles, thus resulting in the formation of thromboses. (3)
They can easily be oxidized, which in turn will weaken their magnetic property. In order to circumvent the above problems, $\mathrm{Fe}$ nanoparticles need to be coated so that they retain their high magnetic moment, and remain nontoxic, biocompatible, and chemically stable.

Gold has been recognized as the best candidate for coating due to its bio-compatibility, functionality with various enzymes, chemical inertness, and flexible geometries such as rings, cages, and tubes. ${ }^{4-9}$ Recently, the synthesis and characterization of gold-coated iron nanoparticles and the study of their magnetic properties have become the focus of many experimental studies. ${ }^{10,11}$ Using microemulsion or reverse micelle method, ${ }^{12}$ Lin et al. were successful in synthesizing gold-coated iron nanoparticles where the peaks corresponding to iron oxide nanoparticles were not seen in the x-ray diffraction (XRD) analysis. This indicates that the gold coating on the iron nanoparticles is protecting them rather well from oxidation. Cho and co-workers reported the synthesis of iron-gold core-shell nanoparticles with large iron cores that exhibit ferromagnetism at room temperature..$^{13}$ In another experimental study, ${ }^{14}$ gold-coated acicular and spherical shaped iron nanoparticles were prepared and their morphology and magnetic properties were characterized using transmission electron microscopy (TEM) and alternate gradient magnetometry. It has been found that the gold-coated nanoparticles were more resistant to oxidation and corrosion than the uncoated particles, and the gold shell was more uniformly distributed on the spherical particles than on the acicular ones.

In spite of these experimental studies, a fundamental understanding of how gold interacts with an iron core is still lacking. For example: (1) Does gold coating enhance or reduce the magnetic moment of iron and how does it change as the thickness of the coating is increased? (2) Do the iron atoms continue to couple ferromagnetically? (3) Does the geometry of iron core change when it is coated with gold? 
(4) How does the reactivity of $\mathrm{Fe}$ clusters toward oxygen change with Au coating? No experiments to our knowledge have measured the magnetic moment of a $\mathrm{Fe}$ core coated with gold. On the theoretical front, very few studies have been carried out on noble metal coated metal nanoparticles. Tight binding based theoretical calculations ${ }^{15}$ were performed to understand the properties of $\mathrm{Cu}$ covered cobalt and $\mathrm{Ag}$ covered cobalt clusters. In a density-functional theory based study, ${ }^{16}$ the different magnetic properties between palladium coated and alloyed nickel clusters were investigated. As to our knowledge, there are no theoretical studies of goldcoated iron clusters. Motivated by the imbalance between the experiments and theoretical studies of the gold-coated iron clusters, and the lack of fundamental understanding of the shell-core interactions, we have initiated a theoretical study of gold-coated iron nanoclusters.

In this paper, we report the results of the first systematic theoretical investigation of the structural and magnetic properties of gold-coated iron nanoclusters at various size ranges and provide answers to the aforementioned important questions on the shell-core interactions. We show that the coating of gold not only prevents the iron core from oxidation but also keeps the strong magnetic nature of iron alive. Our theoretical work not only complements the oxidative properties of gold-coated $\mathrm{Fe}$ nanoparticles but also shows further that the magnetic moment of the iron core is larger than its bulk value. These studies provide some insight for gold-coated $\mathrm{Fe}$ nanoparticles in biomedical applications.

\section{COMPUTATIONAL METHODS}

The focus of this study was to study the magnetic property of Fe nanoparticles and how they are affected by gold coating and reaction with oxygen. Since the origin of magnetism quantum mechanical phenomenon, we used densityfunctional theory (DFT). The ground state geometries of $\mathrm{Fe}_{2}-\mathrm{Au}_{n}$ (n=1-6, and 18) clusters were obtained using GAUSSIAN03 program suite. ${ }^{17}$ The "frozen core" Lanl2dz basis set for Au and 6-311G ${ }^{*}$ basis set for Fe were employed in the calculations. The geometrical parameters of $\mathrm{Fe}_{2}-\mathrm{Au}_{n}$ clusters were completely optimized, without any symmetry constraints and for all the possible spin configurations. The convergence criteria for the gradient force and the energy were set to $10^{-4}$ Hartree/ $\AA$ and $10^{-9}$ Hartree, respectively. For the larger systems $\left(\mathrm{Fe}_{x} \mathrm{Au}_{y}, x=1,13, y=12,42,54,134\right.$; $\mathrm{Fe}_{13} \mathrm{Au}_{42}-\mathrm{O}_{2}$ ), however, GAUSSIAN03 calculations are computationally prohibitive. For these studies, we used a planewave basis set with the projector augmented plane-wave (PAW) method as implemented in the Vienna ab initio Simulation Package (VASP). ${ }^{18}$ We have used supercells with $15 \AA$ vacuum spaces along $x, y$, and $z$ directions for all the calculated structures. The $\Gamma$ point is used to represent the Brillouin zone due to the large supercell. The energy cutoff was set to $400 \mathrm{eV}$ and the convergence in energy and force were $10^{-4} \mathrm{eV}$ and $1 \times 10^{-3} \mathrm{eV} / \AA$, respectively. The generalized gradient approximation (GGA) to DFT was used in all these calculations. The gradient corrected exchange functional due to Becke, ${ }^{19}$ combined with gradient corrected Perdew-Wang ${ }^{20}$ correlation functional (BPW91) were used.

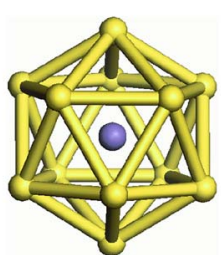

FeAu

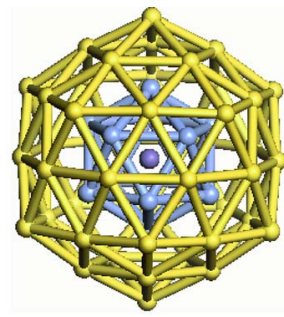

$\mathrm{Fe} @ A u_{12} @ A u_{30} @ A u_{12}$
FIG. 1. (Color online) Geometries of Fe atom wrapped in gold.

The accuracy of our numerical procedure was well tested in our previous studies. .,21-23 $^{23}$

\section{RESULTS}

\section{A. Magnetic moment of $\mathrm{Fe}_{1} \mathrm{Au}_{n}(n=1,12$, and 54) clusters}

Our first objective is to calculate the magnetic moment of a Fe atom interacting with $\mathrm{Au}$ atoms by coating a $\mathrm{Fe}$ atom with successive shells of $\mathrm{Au}$ atoms. We start with a Fe atom first interacting with a single $\mathrm{Au}$ atom and then embedding the $\mathrm{Fe}$ atom inside $\mathrm{Au}$ icosahedra containing 12 and 54 atoms. These clusters are labeled as $\mathrm{Fe}_{1} \mathrm{Au}_{1}, \mathrm{Fe}_{1} @ \mathrm{Au}_{12}$, and $\mathrm{Fe}_{1} @ \mathrm{Au}_{12} @ \mathrm{Au}_{30} @ \mathrm{Au}_{12}$. Figure 1 shows the equilibrium geometries of these complexes while their structural parameters and magnetic moments are listed in Table I. Here, the magnetic moment is obtained using Wigner-Seitz cell partition method while the total magnetic moment includes the contributions from $\mathrm{Fe}$ core and $\mathrm{Au}$ shell. For an isolated $\mathrm{Fe}$ atom, the magnetic moment is $4 \mu_{\mathrm{B}}$ based on the Hund's rule. When one $\mathrm{Au}$ atom is attached to a $\mathrm{Fe}$ atom, a $\mathrm{FeAu}$ dimer is formed with a bond length of $2.330 \AA$. Due to the hybridization between $\mathrm{Au} 6 s$ and $\mathrm{Fe} 3 d$ orbitals, the magnetic moment of $\mathrm{Fe}$ is reduced to $3.442 \mu_{\mathrm{B}}$, and the $\mathrm{Au}$ atom is polarized ferromagnetically with a moment of $0.197 \mu_{\mathrm{B}}$. In $\mathrm{Fe} @ \mathrm{Au}_{12}$ cluster the $\mathrm{Fe}$ atom is fully wrapped in an icosahedral shell. The distance between the Fe atom and the gold shell has increased to $2.713 \AA$. The magnetic moment of the $\mathrm{Fe}$ atom is reduced to $3.0 \mu_{\mathrm{B}}$ and is antiferromagnetically coupled to the Au atoms, each of which carries a moment of $-0.057 \mu_{\mathrm{B}}$. Although the larger distance between $\mathrm{Fe}$ and $\mathrm{Au}$ atoms would cause the $\mathrm{Fe}$ moment to increase, the net reduction in the $\mathrm{Fe}$ moment is a result of hybridization of Fe $3 d$ orbitals with $6 s$ orbitals of the 12 Au atoms.

To see if the moment on Fe will further reduce with the thickness of the gold shell, we added 42 more Au atoms to $\mathrm{Fe} @ \mathrm{Au}_{12}$ thus forming $\mathrm{Fe}_{1} @ \mathrm{Au}_{12} @ \mathrm{Au}_{30} @ \mathrm{Au}_{12}$ cluster. In this case, the $\mathrm{Fe}$ atom is wrapped with two complete icosahedral shells. The distance between $\mathrm{Fe}$ atom and the first $\mathrm{Au}$ shell is $2.718 \AA$, the Au-Au bond lengths in the first and second shell are 2.864 and $2.875 \AA$, respectively. The distance between these two Au shells is $2.741 \AA$. The magnetic moment of the Fe atom is still $3.0 \mu_{\mathrm{B}}$; whereas, the induced moment on Au atoms is totally changed. In the first shell, all the $12 \mathrm{Au}$ atoms are equivalent with the moment of $0.034 \mu_{\mathrm{B}}$. In the second shell, there are two unequivalent $\mathrm{Au}$ 
TABLE I. Bond length $R(\AA)$ and magnetic moment $\mu\left(\mu_{\mathrm{B}}\right)$ for Fe atom wrapped with gold.

\begin{tabular}{|c|c|c|c|c|c|}
\hline & $\mathrm{Fe}_{1}$ & $\mathrm{Fe}_{1} \mathrm{Au}_{1}$ & $\mathrm{Fe}_{1} @ \mathrm{Au}_{12}$ & $\mathrm{Fe}_{1} @ \mathrm{Au}_{12} @ \mathrm{Au}_{30} @ \mathrm{Au}_{12}$ & Comparison \\
\hline & & & & & $\begin{array}{c}3.05(\text { Fe impurity in } \mathrm{Au} \\
\text { bulk })^{\mathrm{a}}\end{array}$ \\
\hline \multirow[t]{3}{*}{$\mu_{\mathrm{Fe}}$} & 4.0 & 3.442 & 3.00 & 3.0 & $2.95(\mathrm{Fe}-\mathrm{Au} \text { alloy })^{\mathrm{a}}$ \\
\hline & & & & & $2.84(\mathrm{Fe}-\mathrm{Au} \text { overlayer })^{\mathrm{b}}$ \\
\hline & & & & & $2.80(\mathrm{Fe}-\mathrm{Au} \text { multilayer })^{\mathrm{c}}$ \\
\hline \multirow[t]{3}{*}{$\mu_{\mathrm{Au}}$} & & 0.197 & -0.057 & 0.034 (1st shell) & $<0.07$ (overlayer) $^{\mathrm{d}}$ \\
\hline & & & & 0.012 (2nd shell) & $0.036-1.105$ (multilayers) $^{\mathrm{c}}$ \\
\hline & & & & 0.005 (3rd shell) & \\
\hline$R_{\mathrm{Fe}-\mathrm{Au}}$ & & 2.330 & 2.713 & 2.718 & \\
\hline \multirow[t]{3}{*}{$R_{\mathrm{Au}-\mathrm{Au}}$} & & & 2.852 & 2.684 (1st shell) & \\
\hline & & & & 2.875 (2nd shell) & \\
\hline & & & & 2.741 (1st, 2nd shell) & \\
\hline
\end{tabular}

${ }^{\mathrm{a}}$ Reference 24.

${ }^{\mathrm{b}}$ Reference 25 .

${ }^{\mathrm{c}}$ Reference 26.

${ }^{\mathrm{d}}$ Reference 22 . atoms $(30+12)$ with the moment of 0.012 and $0.005 \mu_{\mathrm{B}}$. It is interesting to note that the moment of a Fe impurity in bulk $\mathrm{Au}$ is found to be $3.05 \mu_{\mathrm{B}},{ }^{24}$ while the moment of $\mathrm{Fe}$ is Fe-Au alloy is $2.95 \mu_{\mathrm{B}} .{ }^{24}$ In the overlayer and multilayers, the Fe moment is about $2.8 \mu_{\mathrm{B}}$ and the induced Au moment is about $0.036 \sim 0.105 \mu_{\mathrm{B}} .{ }^{25,26}$ Thus, one could conclude that the magnetic moment of a $\mathrm{Fe}$ atom in Au has saturated to a value of about $3.0 \mu_{\mathrm{B}}$. This is particularly important since the magnetic moment of $\mathrm{Fe}$ in the bulk is only $2.2 \mu_{\mathrm{B}}$.

\section{B. Magnetic coupling between $\mathrm{Fe}$ atoms in $\mathrm{Fe}_{2} \mathrm{Au}_{n}$ $(n=1-6,18)$, clusters}

Once it is established that the magnetic moment of the $\mathrm{Fe}$ atom interacting with $\mathrm{Au}$ is even higher than that in the bulk $\mathrm{Fe}$, it is important to examine if the interaction between the $\mathrm{Fe}$ atoms remains ferromagnetic. We study this by sequential addition of $\mathrm{Au}$ atoms to a $\mathrm{Fe}_{2}$ dimer. In Fig. 2, we show the ground state geometries for $\mathrm{Fe}_{2} \mathrm{Au}_{n}(n=0-6)$ clusters. For
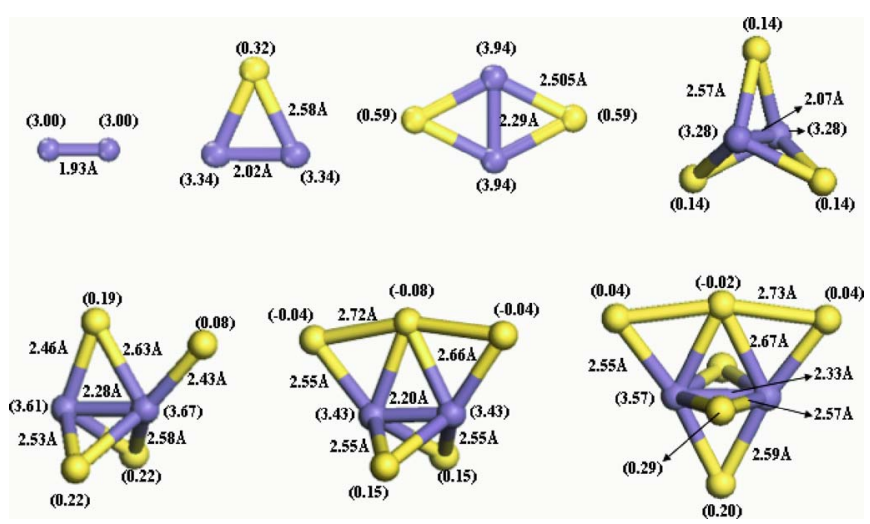

FIG. 2. (Color online) Geometry of $\mathrm{Fe}_{2} \mathrm{Au}_{n}(n=0-6)$ clusters. The numbers in parentheses are magnetic moments (in $\mu_{\mathrm{B}}$ ) located on $\mathrm{Fe}$ and $\mathrm{Au}$ atoms.
$\mathrm{Fe}_{2}$, the equilibrium bond length is $1.93 \AA$, and each $\mathrm{Fe}$ atom carries the magnetic moment of $3.0 \mu_{\mathrm{B}}$.

When one Au atom is absorbed, the Fe-Fe bond length is elongated to $2.02 \AA$, and accordingly the moment increased to $3.34 \mu_{\mathrm{B}}$. The $\mathrm{Au}$ atom is ferromagnetically polarized with a moment of $0.32 \mu_{\mathrm{B}}$. When the second $\mathrm{Au}$ atom is added, the $\mathrm{Fe}-\mathrm{Fe}$ bond length is increased further to $2.29 \AA$, and the moment on $\mathrm{Fe}$ atom becomes $3.94 \mu_{\mathrm{B}}$. However, when the third $\mathrm{Au}$ atom is added, $\mathrm{Fe}_{2}$ molecule becomes more compact with the bond length of $2.07 \AA$ and the moment decreases to $3.28 \mu_{\mathrm{B}}$. The forth $\mathrm{Au}$ atom is on the top site of one $\mathrm{Fe}$ atom which stretches the Fe-Fe bond length to $2.28 \AA$. In this case, two Fe atoms are no longer equivalent, and the average moment of $\mathrm{Fe}$ is $3.64 \mu_{\mathrm{B}}$. Up to now, all the $\mathrm{Au}$ atoms are ferromagnetically polarized with respect to the orientation of magnetic moment on $\mathrm{Fe}$ atoms. This situation is changed when the fifth $\mathrm{Au}$ atom is introduced, where three $\mathrm{Au}$ atoms form a chain with a negative moment, while the other two $\mathrm{Au}$ atoms are separately bonded to $\mathrm{Fe}$, with a positive moment.

The Fe-Fe bond length has decreased marginally to $2.20 \AA$ resulting in a moment of $3.43 \mu_{\mathrm{B}}$. When the sixth $\mathrm{Au}$ atom is added, it elongates the $\mathrm{Fe}-\mathrm{Fe}$ bond length to $2.33 \AA$ and increases the $\mathrm{Fe}$ moment to $3.57 \mu_{\mathrm{B}}$. It is interesting to note here that unlike in the case of $\mathrm{Fe}_{2} \mathrm{Au}_{5}$, there is only one $\mathrm{Au}$ atom that carries a negative moment. With $18 \mathrm{Au}$ atoms absorbed, $\mathrm{Fe}_{2}$ molecule is completely wrapped inside the gold shell. Figure 3 gives the geometry of $\mathrm{Fe}_{2} @ \mathrm{Au}_{18}$ with $\mathrm{C}_{2 v}$ symmetry.

The bond length between $\mathrm{Fe}$ atoms and the moment on $\mathrm{Fe}$ are $2.57 \AA$ and $3.1 \mu_{\mathrm{B}}$, respectively. Therefore, sequential gold coating of $\mathrm{Fe}_{2}$ can tune the bond length as well as the moment. A summary of the effect of gold coating on $\mathrm{Fe}-\mathrm{Fe}$ bond length and Fe moment is given in Fig. 4. Generally, a magnetic moment depends on two competitive basic factors: bond length and coordination number. Larger bond length favors a larger moment, whereas increasing the coordination 


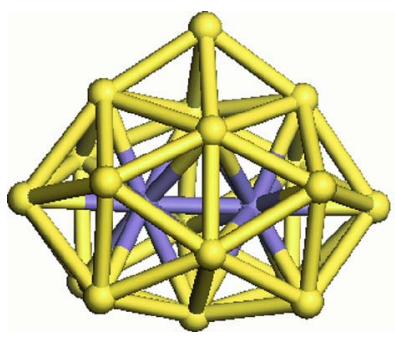

$$
\begin{gathered}
\mu_{\mathrm{Fe}}: 3.10 \mu \mathrm{B} \\
\mu_{\mathrm{Au}}:-0.06-0.1 \mu \mathrm{B} \\
\mathrm{R}_{\mathrm{Fe}-\mathrm{Fe}}: 2.57 \AA \\
\mathrm{R}_{\mathrm{Fe}-\mathrm{Au}}: 2.69 \AA-2.90 \AA
\end{gathered}
$$

FIG. 3. (Color online) Geometry of $\mathrm{Fe}_{2} \mathrm{Au}_{18}$ with $C_{2 v}$ symmetry.

of the atom would reduce its moment. In $\mathrm{Fe}_{2} \mathrm{Au}_{n}$, for $n$ up to 6 , bond length dominates the magnetism, namely, the larger the bond length, the bigger the moment. When $n=18$, the coordination number dominates the magnetism. In this case, $\mathrm{Fe}-\mathrm{Fe}$ bond length reaches $2.57 \AA$, the largest one for all the cases studied, but the moment on Fe atom is only $3.1 \mu_{\mathrm{B}}$, which is comparable to the value of $3.28 \mu_{\mathrm{B}}$ in $\mathrm{Fe}_{2} \mathrm{Au}_{3}$ with the bond length of $2.07 \AA$. Thus, we conclude that the coupling between the Fe atoms remain ferromagnetic independent of the amount of gold and the moment on the Fe atom is still larger than in the bulk.

\section{Magnetic coupling in a Fe core coated with $\mathrm{Au}$ : $\mathrm{Fe}_{13} @ \mathrm{Au}_{42}$ and $\mathrm{Fe}_{13} @ \mathrm{Au}_{134}$}

To examine if a Fe core would also remain magnetic when wrapped in gold, we consider the $\mathrm{Fe}_{13}$ cluster since it has been synthesized using laser vaporization source and found to exhibit much higher intensity in time-of-flight (TOF) mass spectra than its neighbors. ${ }^{27}$ The reactivity and catalysis of $\mathrm{Fe}_{13}$ cluster has also been studied extensively. ${ }^{21,28}$ Our calculations show that the optimized geometry of $\mathrm{Fe}_{13}$ is a distorted icosahedron, where the average bond length between the central $\mathrm{Fe}$ atom and the surface atom is $2.512 \AA$. The average moments on the central and surface $\mathrm{Fe}$ atoms are 2.32 and $3.0 \mu_{\mathrm{B}}$, respectively. Now we explore the changes in the geometry and moment of $\mathrm{Fe}_{13}$ when it is coated with gold. First, we discuss $\mathrm{Fe}_{13} @ \mathrm{Au}_{42}$. We studied three isomers of this complex. The optimized

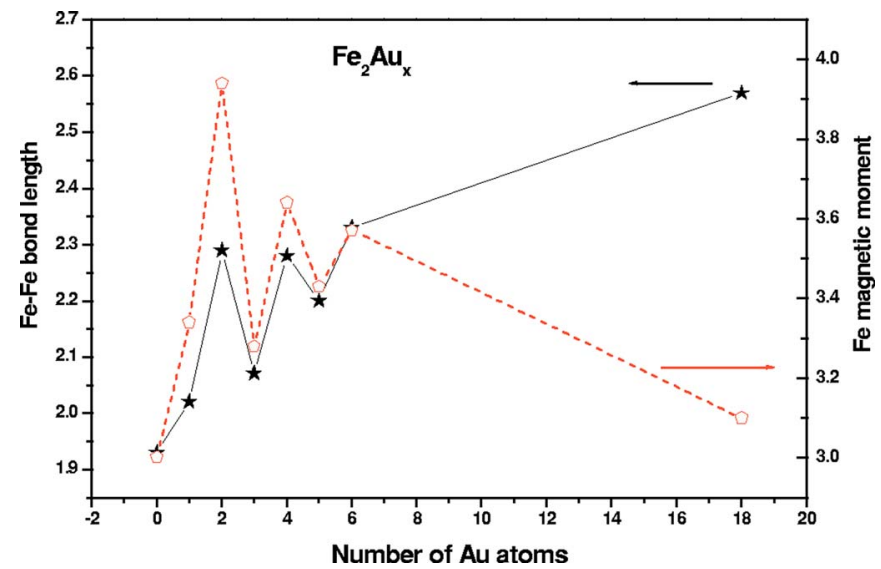

FIG. 4. (Color online) Changes of Fe-Fe bond length (in $\AA$, left axis) and magnetic moment located on $\mathrm{Fe}$ atom (in $\mu_{\mathrm{B}}$, right axis).
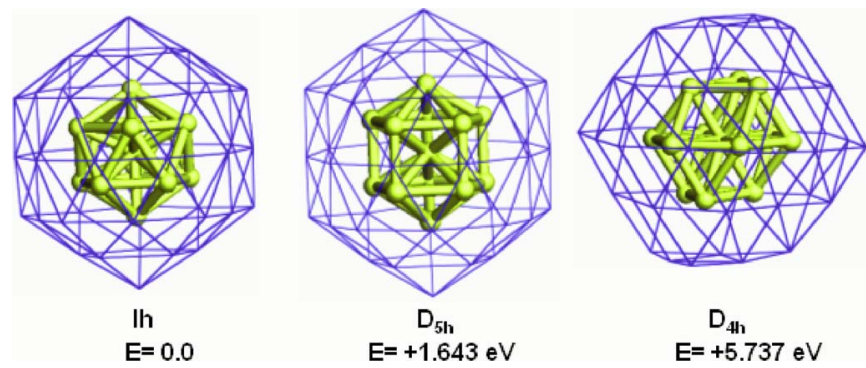

FIG. 5. (Color online) Optimized $\mathrm{Fe}_{13} @ \mathrm{Au}_{42}$ isomers with different symmetry as shown. The relative energy $E$, with respect to the $I_{h}$ structure is also shown.

geometries of these isomers are shown in Figure 5, whose initial geometries were icosahedron, decahedron, and octahedron, respectively. The lowest energy structure of $\mathrm{Fe}_{13} @ \mathrm{Au}_{42}$ is an icosahedron with $I_{h}$ symmetry. It is noteworthy here that while the bare $\mathrm{Fe}_{13}$ is a distorted icosahedron, gold coating of $\mathrm{Fe}_{13}$ has resulted in a perfect $I_{h}$ symmetric structure. This observation is in agreement with the experimental findings that $\mathrm{Fe}-\mathrm{Au}$ particles display icosahedral structure. ${ }^{29}$

In the $D_{5 h}$ isomer, the $\mathrm{Fe}_{13}$ core is a decahedron while the Au shell becomes an icosahedron cage. In the $D_{4 h}$ isomer, both $\mathrm{Fe}_{13}$ core and $\mathrm{Au}$ shell are distorted from the initial octahedral structures. In the ground state geometry of the $I_{h}$ structure, compared to the bare $\mathrm{Fe}_{13}$ cluster, the bond length of the $\mathrm{Fe}_{13}$ core is expanded by $3.2 \%$ after gold coating. While the magnetic moment of the central Fe atom increased to $2.384 \mu_{\mathrm{B}}$, the moment of the outer Fe atoms is reduced to $2.923 \mu_{\mathrm{B}}$ from $3.0 \mu_{\mathrm{B}}$ due to the interactions with the gold shell. Fe-Au bond length is found to be $2.83 \AA$, comparable to the values of 2.69-2.90 $\AA$ found in $\mathrm{Fe}_{2} @ \mathrm{Au}_{18}$, as we discussed above. For the gold-coating shell of $\mathrm{Au}_{42}$, there are two subshells composed of $(30,12)$ atoms, the corresponding induced moment in these two subshells are 0.018 and $0.014 \mu_{\mathrm{B}}$, respectively.

From the studies of $\mathrm{Fe}_{2} @ \mathrm{Au}_{18}$ and $\mathrm{Fe}_{13} @ \mathrm{Au}_{42}$, we can see that the large magnetic moment of $\mathrm{Fe}$ are more or less preserved after being coated completely with a single shell of gold atoms. To see if increasing the thickness of gold coating can retain the large magnetic moment of the iron core, we added another shell of 92 gold atoms to the $\mathrm{Fe}_{13} @ \mathrm{Au}_{42}$ cluster resulting in $\mathrm{Fe}_{13} @ \mathrm{Au}_{134}$ having icosahedral symmetry. The coating consists of five subshells $(30,12,20,60$, and 12). Figure 6 shows the optimized geometry constrained to having the $I_{h}$ symmetry. The addition of extra gold layers onto the $\mathrm{Fe}_{13} @ \mathrm{Au}_{42}$ was found to have negligible effect on the bond length and the magnetic moments of the $\mathrm{Fe}_{13}$ core. For example, the distance from the central Fe atom to the outer Fe atom becomes $2.438 \AA$ and the core-shell distance becomes $2.820 \AA$ which are quite close to the values of 2.467 and $2.830 \AA$, respectively, in $\mathrm{Fe}_{13} @ \mathrm{Au}_{42}$. Due to the extra gold layers, the moment on the central Fe atom changes from $2.384 \mu_{\mathrm{B}}$ to $2.357 \mu_{\mathrm{B}}$, while the moment on the $\mathrm{Fe}$ atom on the outer shell changes from $2.932 \mu_{\mathrm{B}}$ to $2.801 \mu_{\mathrm{B}}$. The induced magnetic moments in the five subshells of gold are $0.015,0.012,0.010,0.007$, and $0.003 \mu_{\mathrm{B}}$, respectively.

In Table II, we summarize the main results for $\mathrm{Fe}_{13}$, $\mathrm{Fe}_{13} @ \mathrm{Au}_{42}$, and $\mathrm{Fe}_{13} @ \mathrm{Au}_{134}$ clusters. For a thickly coated 

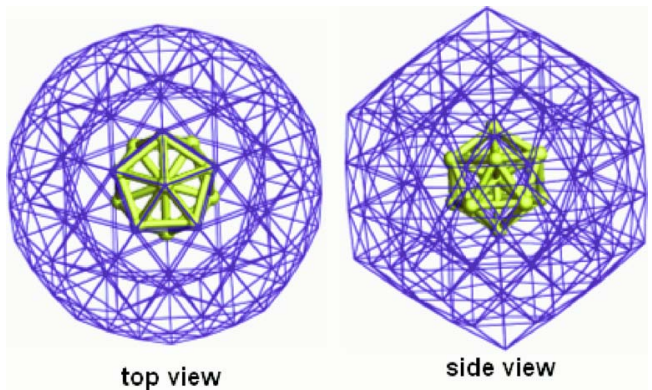

FIG. 6. (Color online) Optimized geometry of $\mathrm{Fe}_{13} @ \mathrm{Au}_{134}$.

shell, it is clear that the induced moment on gold shells is mainly on the interface layers, and there are no moments on the outermost layers. Hence, this core-shell complex looks like fferromagnetic $\mathrm{Fe}$ core+weakly polarized $\mathrm{Au}$ layers + nonmagnetic Au layers\}. Therefore, the thickness of the gold shell has some effect only on the induced moment distribution in the gold shells but has little effect on the magnetic moment of the Fe core, whose large magnetic moment is very well retained. This is a very desirable property in magnetic drug delivery and hyperthermia treatment.

\section{Oxidation of $\mathrm{Fe}_{13}$ and $\mathrm{Fe}_{13} @ \mathrm{Au}_{42}$ clusters}

It is well known that iron oxidizes easily and this oxidation adversely affects its magnetic properties. For example, $\mathrm{Fe}_{13}$ cluster reacts with oxygen forming stable $\mathrm{Fe}_{13} \mathrm{O}_{8}$ cluster ${ }^{21}$ which greatly reduces the magnetic moment as compared to $\mathrm{Fe}_{13}$. To gain a fundamental understanding of this process, we have reacted $\mathrm{Fe}_{13}$ and $\mathrm{Fe}_{13} @ \mathrm{Au}_{42}$ cluster with an oxygen molecule.

We first discuss the interaction of $\mathrm{O}_{2}$ with $\mathrm{Fe}_{13}$. The starting and optimized geometries of $\mathrm{Fe}_{13} \mathrm{O}_{2}$ are given in Fig. 7 (a). Note that $\mathrm{O}_{2}$ dissociates and binds with the surface $\mathrm{Fe}$ atoms strongly with a binding energy of $8.04 \mathrm{eV}$. The total magnetic moment of $\mathrm{Fe}_{13} \mathrm{O}_{2}$ is $38 \mu_{\mathrm{B}}$, which is reduced by $4 \mu_{\mathrm{B}}$ as compared to the magnetic moment of $\mathrm{Fe}_{13}$. The study of the possible absorption sites of $\mathrm{O}_{2}$ on $\mathrm{Fe}_{13} @ \mathrm{Au}_{42}$ is difficult as there are 12 vertices and 30 bridge sites to consider. However, the knowledge of the electronic structure of

TABLE II. Bond length (in $\AA$ ) and magnetic moment (in $\mu_{\mathrm{B}}$ ) for $\mathrm{Fe}_{13} @ \mathrm{Au}_{n}$.

\begin{tabular}{lccc}
\hline \hline & $\mathrm{Fe}_{13}$ & $\mathrm{Fe}_{13} @ \mathrm{Au}_{30} @ \mathrm{Au}_{12}$ & $\mathrm{Fe}_{13} @ \mathrm{Au}_{30} @ \mathrm{Au}_{12} @ \mathrm{Au}_{60} @ \mathrm{Au}_{12}$ \\
\hline$\mu_{\mathrm{Fe} 1}$ & 2.32 & 2.384 & 2.357 \\
$\mu_{\mathrm{Fe} 2}$ & 3.00 & 2.923 & 2.801 \\
$\mu_{\mathrm{Au}}$ & & 0.018 (1st shell) & 0.015 (1st shell) \\
& & 0.014 (2nd shell) & 0.012 (2nd shell) \\
& & & 0.010 (3rd shell) \\
& & & 0.007 (4th shell) \\
& & & 0.003 (5th shell) \\
$R_{\mathrm{Fe} 1}$ & 2.390 & 2.457 & 2.438 \\
$R_{\mathrm{Fe} 2}$ & 2.512 & 2.594 & 2.543 \\
$R_{\mathrm{Fe}-\mathrm{Au}}$ & & 2.830 & 2.820 \\
\hline \hline
\end{tabular}
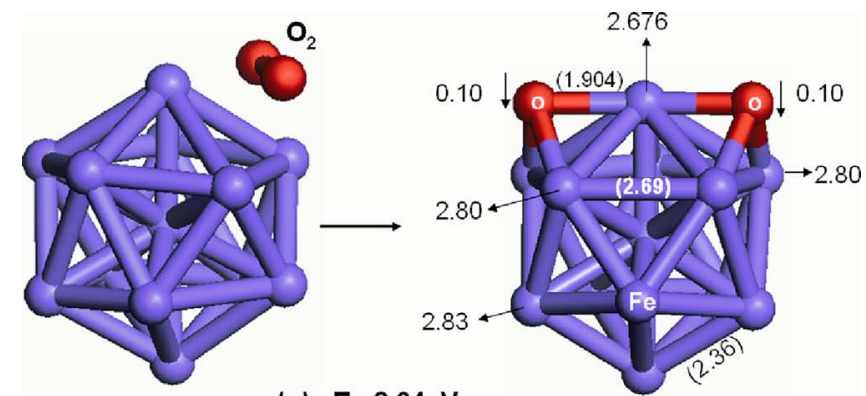

(a) $\mathrm{E}=\mathbf{8 . 0 4 \mathrm { eV }}$
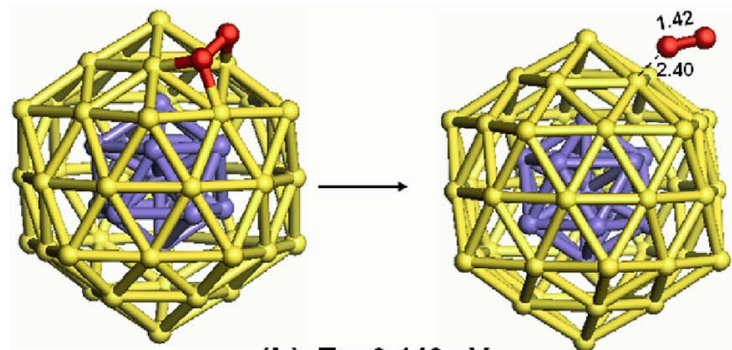

(b) $E=0.143 \mathrm{eV}$

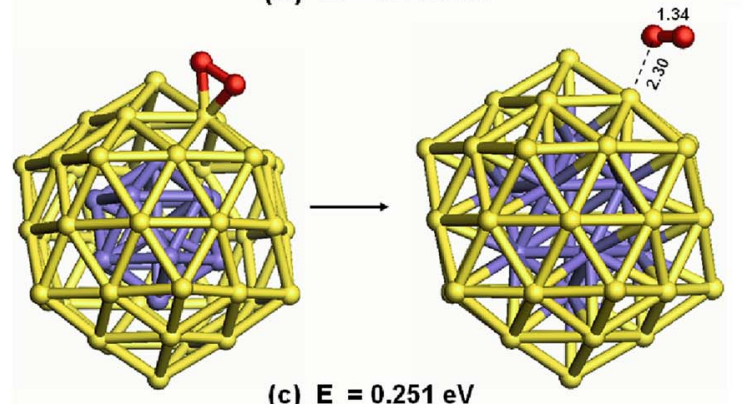

(c) $E=0.251 \mathrm{eV}$

FIG. 7. (Color online) Initial and optimized geometries for $\mathrm{Fe}_{13}-\mathrm{O}_{2}$ and $\mathrm{Fe}_{13} @ \mathrm{Au}_{42}-\mathrm{O}_{2}$. The bond length (in $\AA$, the numbers in parentheses) and moment (in $\mu_{\mathrm{B}}$ ) are given for $\mathrm{Fe}_{13}-\mathrm{O}_{2}$. The bond length of $\mathrm{O}_{2}$ and the distance between $\mathrm{O}_{2}$ and $\mathrm{Au}$ shell are shown in (b) and (c).

$\mathrm{Fe}_{13} @ \mathrm{Au}_{42}$ helps. The coating of $\mathrm{Fe}_{13}$ by Au allows charges to be transferred from $\mathrm{Fe}_{13}$ core to the coating shell. This is because $\mathrm{Au}$ is the most electronegative metal, comparable to selenium, and is only slightly more electropositive than sulfur and iodine. Therefore, it can form ionic compounds such as $\mathrm{Au}^{-} \mathrm{Cs}^{+}{ }^{30}$ Similar charge transfer was also found in the gold-coated $\mathrm{SiO}_{2}$ system. ${ }^{5}$ We found that in $\mathrm{Fe}_{13} @ \mathrm{Au}_{42}$, the transferred charges are primarily accumulated on the bridge sites. Therefore these bridge sites are expected to be the preferred absorption sites for $\mathrm{O}_{2} .{ }^{22}$

We have tried two different initial absorption configurations as shown in Figs. 7(b) and 7(c). In both cases, $\mathrm{O}_{2}$ interacts weakly with $\mathrm{Fe}_{13} @ \mathrm{Au}_{42}$. The interaction energies are $0.143 \mathrm{eV}$ and $0.251 \mathrm{eV}$ and the distances between the $\mathrm{Au}$ and $\mathrm{O}$ atom are respectively 2.4 and $2.3 \AA$. This is in agreement with experiments ${ }^{12,14}$ where nanoparticles coated with $\mathrm{Au}$ have been found to be resistant to corrosion.

\section{DISCUSSIONS AND SUMMARY}

Although gold-coated Fe particles, usually studied in experiments, have a diameter of about $10 \mathrm{~nm}$, the clusters we 
have studied here, namely, $\mathrm{Fe}_{13} @ \mathrm{Au}_{42}$ and $\mathrm{Fe}_{13} @ \mathrm{Au}_{134}$, have diameters of 1.036 and $1.626 \mathrm{~nm}$, respectively. There are two main reasons why we used these small systems: (1) Smaller size particles may have an advantage in penetrating the crowded environments such as biological milieu of cells and live tissues and can be more effective for drug delivery. In fact, there are some regions in the human body (e.g., inside kidney tubules and those beyond the blood brain barrier) that have special types of cell to cell contacts called the zonulae occludentes, which are about $1 \mathrm{~nm}$ wide. (2) Small size allows us to do accurate calculations. It would be ideal if one could carry out a calculation on a $10 \mathrm{~nm}$ size goldcoated iron nano nanoparticles using the same level of theory as used here; however, such a calculation is beyond the scope of present computer power. Our systematic studies on the small size clusters, however, allow us to draw some general conclusions that are valid for larger particles: (1) The magnetic moment of a $\mathrm{Fe}$ atom is enhanced over bulk value and remains insensitive to the amount of gold coating. (2) The coupling between the Fe atoms remains ferromagnetic irrespective of the number of gold layers. (3) The iron core remains magnetic with a large magnetic moment. (4) Coating of gold also prevents iron from oxidation and may also prevent their coalescence and formation of thromboses in the body. (5) Gold coating improves the biocompatibility and provides a platform for magnetic particles to be functionalized.

\section{ACKNOWLEDGMENTS}

The authors thank the crew of the Center for Computational Materials Science, the Institute for Materials Research, Tohoku University (Japan), for their continuous support of the HITACH SR8000 supercomputing facility. Q. Sun thanks M. Hajaligol, B. Reddy, C. Gonzalez, and V. Mujica for stimulating discussions.
*Corresponding author. Electronic address: qsun@vcu.edu

${ }^{1}$ S. Mornet, S. Vasseur, F. Grasset, and E. Duguet, J. Mater. Chem. 14, 2161 (2004).

${ }^{2}$ P. Tartaj, M. Morales, S. V. Verdaguer, T. G. Carreño, and C. J. Serna, J. Phys. D 36, R182 (2003).

${ }^{3}$ Q. A. Pankhurst, J. Connolly, S. K. Jones, and J. Dobson, J. Phys. D 36, R167 (2003).

${ }^{4}$ R. F. Service, Nature (London) 306, 2035 (2004).

${ }^{5}$ Q. Sun, Q. Wang, B. K. Rao, and P. Jena, Phys. Rev. Lett. 93, 186803 (2004)

${ }^{6}$ J. Aizpurua, P. Hanarp, D. S. Sutherland, M. Käll, G. W. Bryant, and F. J. García de Abajo, Phys. Rev. Lett. 90, 057401 (2003).

${ }^{7}$ Q. Sun, Q. Wang, P. Jena, R. Note, J. Z. Yu, and Y. Kawazoe, Phys. Rev. B 70, 245411 (2004).

${ }^{8}$ M. P. Johansson, D. Sundholm, and J. Vaara, Angew. Chem., Int. Ed. 43, 2678 (2004).

${ }^{9}$ Y. Kondo and K. Takayanagi, Science 289, 606 (2000).

${ }^{10}$ W. L. Zhou, E. E. Carpenter, J. Lin, A. Kumbhar, J. Sims, and C. J. O'Connor, Eur. Phys. J. D 16, 289 (2001).

${ }^{11}$ E. E. Carpenter, J. Magn. Magn. Mater. 225, 17 (2001).

${ }^{12}$ J. Lin, W. Zhou, A. Kumbhar, J. Wiemann, J. Fang, E. E. Carpenter, and C. J. O'Connor, J. Solid State Chem. 159, 26 (2001).

${ }^{13}$ S.-J. Cho, J.-C. Idrobo, J. Olamit, K. Liu, N. D. Browning, and S. M. Kauzlarich, Chem. Mater. 17, 3181 (2005).

${ }^{14}$ M. Chen, S. Yamamuro, D. Farrell, and S. A. Majetich, J. Appl. Phys. 93, 7551 (2003).
${ }^{15}$ J. Guevara, A. M. Llois, and M. Weissmann, Phys. Rev. Lett. 81, 5306 (1998).

${ }^{16}$ Q. Wang, Q. Sun, J. Z. Yu, Y. Hashi, and Y. Kawazoe, Phys. Lett. A 267, 394 (2000).

${ }^{17}$ M. J. Frischl et al., GAUSSiAn03 (Gaussian, Pittsburgh, 2003).

${ }^{18}$ G. Kresse and J. Furthmüller, Phys. Rev. B 54, 11169 (1996).

${ }^{19}$ A. D. Becke, Phys. Rev. A 38, 3098 (1988).

${ }^{20}$ J. P. Perdew and Y. Wang, Phys. Rev. B 45, 13244 (1992).

${ }^{21}$ Q. Wang, Q. Sun, M. Sakurai, J. Z. Yu, B. L. Gu, K. Sumiyama, and Y. Kawazoe, Phys. Rev. B 59, 12672 (1999).

${ }^{22}$ Q. Sun, P. Jena, Y. D. Kim, M. Fischer, and G. Gantefor, J. Chem. Phys. 120, 6510 (2004).

${ }^{23}$ Q. Sun, Q. Wang, Y. Kawazoe, and P. Jena, Eur. Phys. J. D 29, 231 (2004)

${ }^{24}$ S. Khmelevskyi, J. Kudrnovsky, B. L. Gyorffy, P. Mohn, V. Drchal, and P. Weinberger, Phys. Rev. B 70, 224432 (2004).

${ }^{25}$ C. M. Fang, R. A. de Groot, M. M. J. Bischoff, and H. van Kempen, Phys. Rev. B 58, 6772 (1998).

${ }^{26}$ J. Wang, Z. Li, Q. Sun, and Y. Kawazoe, J. Magn. Magn. Mater. 183, 42 (1998).

${ }^{27}$ M. Sakurai, K. Watanabe, K. Sumiyama, and K. Suzuki, J. Chem. Phys. 111, 235 (1999).

${ }^{28}$ F. Huisken, B. Kohn, R. Alexandrescu, and I. Morjan, J. Chem. Phys. 113, 6579 (2000).

${ }^{29}$ D. K. Saha, K. Koga, and H. Takeob, Eur. Phys. J. D 9, 539 (1999).

${ }^{30}$ G. C. Bond, Catal. Today 72, 5 (2002). 